\title{
Reality of Kawasaki disease epidemiology
}

\author{
Gi Beom Kim, MD, PhD \\ Department of Pediatrics, Seoul National University Children's Hospital, Seoul National University College of Medicine, Seoul, Korea
}

Epidemiologic studies of Kawasaki disease (KD) have shown a new pattern or change of its occurrence suggestive of its pathophysiology or risk factors from the first patient with KD reported in 1961. The incidence of KD in Northeast Asian countries including Japan, South Korea, China, and Taiwan is 10-30 times higher than that in the United States and Europe. Knowing the true epidemiology of KD in each country and the availability of publications of KD epidemiology also could benefit general health care providers and general population. This would enable the early detection and treatment of KD, ultimately reducing the incidence of coronary artery complications and mortality. Therefore, efforts to investigate the true epidemiology of KD should be continued in every country using a questionnaire survey, National Health Insurance system data, or combined methods depending on each country's medical environment to ensure high-quality care of patients with KD.

Key words: Kawasaki disease, Epidemiology, Seasonal variation, Surveys and questionnaires, National Health Insurance

\section{Graphical Abstract}

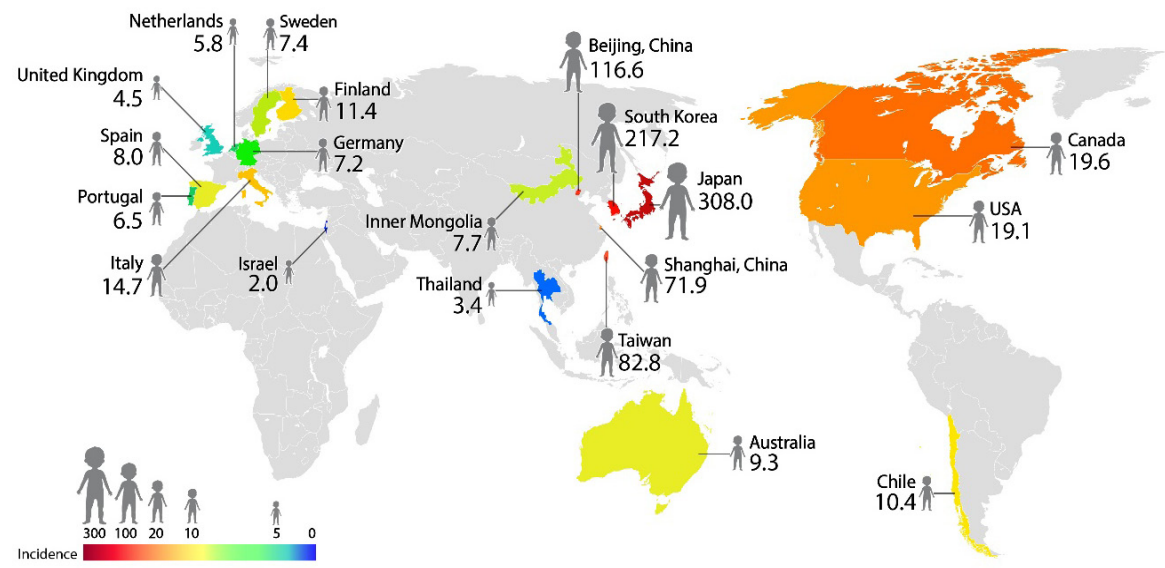

The incidence of Kawasaki disease (KD) worldwide. The incidence of KD per 100,000 less than 5 -year-olds has various geographic occurrence patterns. It is much higher in Northeast Asian countries including Japan, South Korea, China, and Taiwan, 10-30 times higher than that of KD in North America and Europe.

\section{Introduction}

Kawasaki disease $(\mathrm{KD})$ is an acute febrile systemic vasculitis that predominantly occurs in children younger than 5 years of age and the most common acquired heart disease during childhood in most industrialized countries. ${ }^{1)}$ Coronary artery abnormalities, the well-known
Corresponding author: Gi Beom Kim, MD, PhD Department of Pediatrics, Seoul National University Children's Hospital, Seoul National University School of Medicine, 101 Daehak-ro, Jongno-gu, Seoul 03080, Korea

Tel: +82-2-2072-0266

Fax: +82-2-743-3455

E-mail: ped9526@snu.ac.kr

https://orcid.org/0000-0002-7880-280X

Received: 15 February, 2019

Revised: 16 June, 2019

Accepted: 22 June, 2019

\section{Copyright (c) 2019 by The Korean Pediatric Society}

This is an open-access article distributed under the terms of the Creative Commons Attribution NonCommercial License (http://creativecommons.org/ licenses/by-nc/4.0/) which permits unrestricted noncommercial use, distribution, and reproduction in any medium, provided the original work is properly cited. 
complication of $\mathrm{KD}$, occur in up to $15 \%-25 \%$ of patients if $\mathrm{KD}$ is not treated on time. ${ }^{2,3)}$ However, the etiology of KD remains unclear, and many researchers worldwide seek to identify the exact pathophysiology of, genetic profiles of, and new treatment strategies for $\mathrm{KD}$.

What is the benefit of elucidating the epidemiology of KD? Knowing the true epidemiology of any disease is basic to understanding it. It also enables the identification of new patterns or changes in disease occurrence and infers its pathophysiology or risk factors. Unfortunately, a large number of children with KD are still being misdiagnosed with other infectious diseases in many developing countries, including South Korea. ${ }^{4}$ Knowing the true epidemiology of KD in each country could be beneficial to general health care providers including pediatricians and also elucidate the $\mathrm{KD}$ burden in acute treatment settings and the prevalence of long-term adult coronary artery disease. ${ }^{4,5}$ Therefore, efforts to investigate the true epidemiology of KD should be continued in every country to ensure high-quality care of affected patients.

\section{History of KD epidemiology}

From the first patient with KD reported in 1961 and the 50 patients published in 1967 by Dr. Tomisaku Kawasaki over the following 5 years, $\mathrm{KD}$ has been known to Japanese doctors. ${ }^{6)}$ From these case series, a nationwide epidemiologic survey has been performed every 2 years in Japan since 1970; to date, more than 300,000 patients have been reported. ${ }^{7)} \mathrm{KD}$ cases were recognized on every continent by the 1980s. To date, KD has been reported from more than 60 countries across all continents and has been recognized and published increasingly in developing countries. ${ }^{4,7}$ In South Korea, nationwide surveys for KD started in 1994 using KD patient data from all resident-training hospitals in 1991-1993 and have been conducted every 3 years since. ${ }^{8)}$ Taiwan started a national surveillance program for KD in 1995 using data collected from the National Health Insurance database, which is separate from those of Japan and South Korea.

\section{Method of assessing KD epidemiology}

Methods used to determine KD epidemiology differ among countries according to each country's medical environment; therefore, epidemiological comparisons among countries should consider differences in epidemiological methods and the completeness of diagnostic ascertainment and patient reporting. ${ }^{2)}$ The most frequently used method involves using active nationwide surveys as in Japan and South Korea. ${ }^{8,9)}$ The definite merit of this modality is that we can obtain various and detailed data of $\mathrm{KD}$ occurrence including laboratory data, coronary artery complications, and detailed other complications from the tailored questionnaire. From the detailed data, we can infer the pathophysiology and risk factors of KD occurrence and complications. The most important factors in obtaining an accurate incidence are recruiting hospitals to treat as many KD patients as possible and improve the nationwide survey response rate. The survey's success depends on each hospital's active participation and principal investigator's effort to obtain the data. The response rate in Japan was 71.6\% from the 2011-2012 nationwide survey and 74.9\% from the 2013-2014 nationwide survey. ${ }^{9010}$ In South Korea, the response rate was $87 \%$ from the 2009-2011 nationwide survey and 94.8\% from the 2012-2014 nationwide survey. ${ }^{8,11}$ These factors that affect the incidence of $\mathrm{KD}$ are inborn drawbacks of a nationwide survey. The other problem is that the diagnostic accuracies of KD among hospitals could be quite diverse. Some hospitals tend to overdiagnose KD, whereas others underdiagnose it. Therefore, a nationwide survey cannot reflect the true incidence of KD despite its traditional value and merit to provide clues about its pathophysiology and risk factors.

The other method of obtaining KD incidence data involves using national health insurance system data as in Taiwan and South Korea. ${ }^{12-15)}$ Its main strength is that it includes the entire population of each country. Because the national health insurance programs of Taiwan and South Korea cover more than 99\% of the population due to mandatory subscription, their use can represent the incidence of KD since they include all patients treated at all hospitals. In South Korea, researchers used the data of patients who received intravenous immunoglobulin under the diagnosis of KD (ICD-10 [International Statistical Classification of Diseases and Related Health Problems, 10th ed], M30.3). ${ }^{13)}$ This method provides much more incidence data of KD compared with nationwide survey method because of the former's imperfect response rate; however, it is also not free of the possibility of the over- or underdiagnosis of KD in the real world. The demerit of this system is that the collected data are mostly simple and usually confined to incidence, age distribution, sex ratio, province distribution, and seasonal variations. Among national health insurance data, some patients with KD who did not receive intravenous immunoglobulin could be missed. For example, $4.6 \%$ of patients with $\mathrm{KD}$ were not treated with intravenous immunoglobulin from the nationwide survey data in 2012-2014 in South Korea, which means that $4.6 \%$ of patients with $\mathrm{KD}$ were not included in the national health insurance data.

Other modalities can reveal the incidence of KD depending on each country's medical system. For example, researchers in the United States have used passive national surveillance data reported to the Centers for Disease Control and Prevention, kids' inpatient database, or nationwide inpatient samples since the mid-1970s. ${ }^{12,16)}$ In China, considering the huge population, a nationwide survey is quite difficult; therefore, they use questionnaire surveys of the KD incidence in each local province questionnaire survey, especially Beijing and Shanghai. ${ }^{177}$ 
Table 1. Incidence of Kawasaki disease by country

\begin{tabular}{|c|c|c|c|c|}
\hline Country & $\begin{array}{c}\text { Incidence } \\
\text { (per 100,000 less than 5-year-olds) }\end{array}$ & Year & Method & Response rate (\%) \\
\hline Japan" & 308 & 2014 & Nationwide survey & 74.9 \\
\hline South Korea ${ }^{13)}$ & 217.2 & 2014 & National health insurance review & NA \\
\hline South Korea ${ }^{8)}$ & 194.7 & 2014 & Nationwide survey & 94.8 \\
\hline Beijing, China) & 116.6 & 2014 & Province questionnaire survey & NA \\
\hline Taiwan ${ }^{15)}$ & 82.8 & 2010 & National health insurance review & NA \\
\hline Shanghai, China ${ }^{17)}$ & 71.9 & 2012 & Province questionnaire survey & NA \\
\hline Canada ${ }^{18)}$ & 19.6 & 2014 & National administrative data & NA \\
\hline United States $^{\mathrm{a})}$ & 19.1 & 2015 & Nationwide inpatient sample & NA \\
\hline |taly ${ }^{20)}$ & 17.6 & 2013 & Province administrative data & NA \\
\hline Italy ${ }^{30)}$ & 14.7 & 2013 & National administrative data & NA \\
\hline Finland $^{21)}$ & 11.4 & 2009 & Hospital discharge database & NA \\
\hline Chile ${ }^{24)}$ & 10.4 & 2011 & National administrative data & NA \\
\hline Australia $^{31)}$ & 9.34 & 2009 & Province administrative data & NA \\
\hline Spain $^{221}$ & 8 & 2014 & Province administrative data & NA \\
\hline Inner Mongolia ${ }^{29)}$ & 7.7 & 2013 & Province administrative data & NA \\
\hline Sweden ${ }^{211}$ & 7.4 & 2009 & Hospital discharge database & NA \\
\hline Germany $^{33)}$ & 7.2 & 2012 & Nationwide survey & 97 \\
\hline Portugal $^{36)}$ & 6.5 & 2011 & Hospital discharge database & NA \\
\hline Netherlands ${ }^{37)}$ & 5.8 & 2012 & Nationwide survey & 93 \\
\hline United Kingdom ${ }^{32)}$ & 4.55 & 2013-2015 & Prospective population-based study & NA \\
\hline Thailand ${ }^{35)}$ & 3.43 & 2002 & Hospital discharge database & NA \\
\hline$|s r a e|^{34, b)}$ & 2.03 & 2012 & Hospital discharge database & NA \\
\hline
\end{tabular}

NA, nonapplicable.

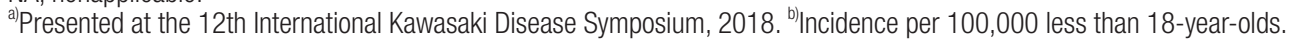

\section{Global incidence of KD}

Diverse epidemiological patterns of KD of each country are described in Table 1. The incidence of KD differs among countries. The incidence of KD in Northeast Asian countries including Japan, South Korea, China, and Taiwan are 10-30 times higher than that in the United Stated or Europe. ${ }^{8,9,16)}$ The other unique finding is that the incidence of $\mathrm{KD}$ is increasing continuously in Northeast Asian countries ${ }^{8,9}$; , however, it is stationary in North America ${ }^{18)}$ and Europe ${ }^{16)}$

The incidence of KD in Japan is increasing continuously; the last known figure was 308 per 100,000 in less than 5-year-olds in $2014,{ }^{9)}$ while that in South Korea is also increasing continuously (194.7 per 100,000 in less than 5-year-olds in 2014). ${ }^{8}$ In China, an epidemiologic study was performed in Beijing and Shanghai using a questionnaire survey, and the incidence of KD was reported as 111.6 and 71.9 per 100,000 less than 5-year-old children, respectively. ${ }^{17)}$ Researchers in Taiwan used a national health insurance review in an KD epidemiology study and reported an incidence of KD of 82.8 per 100,000 less than 5-year-old children in 2010. ${ }^{15)}$

Outside Northeast Asian countries, the incidence of $\mathrm{KD}$ is significantly lower. In North America, KD epidemiological studies have been performed using administrative data, and the incidence of
$\mathrm{KD}$ in the United States was 19.1 per 100,000 less than 5-year-old children in 2015, while those in Canada were 19.6 per 100,000 less than 5-year-old children in 2014. ${ }^{18)}$ Compared with the incidence of $\mathrm{KD}$ in Northeast Asia, the incidence of KD was stationary without significant increases or decreases over several decades. ${ }^{4,16)}$ An interesting finding of $\mathrm{KD}$ epidemiology in the Unites States is that children of Asia-Pacific Islander descent had the highest incidence of KD among various ethnicities. Especially in Hawaii, the incidence of KD in Japanese Americans was similar to that in Japan (greater than 200 per 100,000 less than 5-year-old children), which suggests an in-depth genetic susceptibility of KD occurrence. ${ }^{4,19)}$

Epidemiologic studies are rare in most European countries, and the incidence of KD has been reported as less than 17.6 per 100,000 less than 5-year-olds, ${ }^{20)}$ remaining stationary without significant increases or decreases as in North America. ${ }^{4,21,22}$ In Latin America, no systematic epidemiological study of $\mathrm{KD}$ has been performed in each country, although the incidence of KD has been reported sporadically in several countries. ${ }^{23,24)}$ The recently founded Latin American Kawasaki Disease Network (REKAMLATINA) is expected to improve the understanding of KD epidemiology in Latin America. Twenty Latin American countries joined in this project and have been using this multinational database since $2013 .{ }^{25)}$ 


\section{What KD epidemiology suggests clinical meaning?}

National KD epidemiologic studies have shown diverse disease patterns and changes of KD symptoms, signs, and laboratory findings for several decades. These historical changes modified the diagnostic criteria of KD over time. For example, the 2017 American Heart Association guideline suggested that in the presence of greater than 4 principal clinical symptoms, particularly when the patient shows redness and swelling of the hands and feet, the diagnosis of KD may be made with only 4 days of fever. ${ }^{2)}$ They also suggested that experienced clinicians who have treated many $\mathrm{KD}$ patients may make the diagnosis of KD in rare instances with only 3 days of fever in the presence of classic clinical symptoms and signs. ${ }^{2)}$

$\mathrm{KD}$ epidemiological studies examined the pathophysiology of or risk factors for KD. Seasonal variations in different countries have been the major findings of KD epidemiological studies. Regions in the extratropical northern hemisphere including Japan, South Korea, and the United States have experienced a peak in $\mathrm{KD}$ in the winter and a second peak in the summer in Japan and South Korea and in the spring in the United States. ${ }^{2,8,9,19)}$ However, seasonal variation in the tropics and the extratropical southern hemisphere is not evident. ${ }^{2)}$ Several epidemiological studies demonstrated that KD is associated with preceding respiratory illness. ${ }^{2,26,27)}$

The other important fact of KD epidemiology is that it occurs predominantly in Northeast Asians and Japanese Americans also showed a high incidence in the United States as in Japan ${ }^{4,19}$ These 2 unique findings in the KD epidemiological studies of seasonal variation and geographical patterns of occurrence have been suggested since many infectious agents activate innate and adaptive immune system and provoke KD in genetically susceptible patients. ${ }^{2,7,28)}$

Knowing the true epidemiology of KD in each country and the availability of related publications could also benefit general health care providers including pediatricians and parents of KD patients. KD vigilance in general health care providers and the general population definitely could encourage the early detection and treatment of KD, subsequently reducing coronary artery complication and mortality rates. ${ }^{4,5}$ For example, the incidence of giant aneurysm decreased from $0.26 \%$ in the 2009-2011 nationwide survey to $0.16 \%$ in the 2012-2014 nationwide survey in South Korea, accompanied by the increased KD incidence ${ }^{8,11)}$

\section{What could be the best epidemiological study of KD?}

As mentioned above, the success of epidemiological studies depends on the completeness of $\mathrm{KD}$ diagnostic evaluation and patient reporting. In the nationwide survey of $\mathrm{KD}$, the most important point is achieving a 100\% response rate from all hospitals treating acute KD. However, achieving a 100\% response rate is impossible in the real world because a nationwide survey requires very active participation from each hospital. For an epidemiological study using national health insurance system data, the most critical point is recruiting all $\mathrm{KD}$ patients treated with or without intravenous immunoglobulin and gathering as much epidemiologically detailed data as possible.

Regarding basic epidemiological data including KD incidence, age, sex distribution, and seasonality, an epidemiological study using National Health Insurance system would be the best modality if we could access the data of all KD patients. Detailed epidemiologic data including each patient's symptoms, signs, laboratory findings, echocardiographic findings, and other combined morbidities; thus, the nationwide questionnaire survey has strong benefits of revealing disease changes and the possible pathogenesis of $\mathrm{KD}$. Therefore, these 2 epidemiologic modalities should be combined to reveal the true epidemiology of $\mathrm{KD}$.

\section{Conclusions}

Epidemiological studies of KD have shown new patterns of or changes to $\mathrm{KD}$ occurrence and supported to infer pathophysiology or risk factors of KD. Therefore, the effort to investigate true epidemiology of KD should be continued in every country to ensure high-quality care of patients with KD using questionnaire surveys, national health insurance system data, or combined methods depending on each country's medical environment.

\section{Conflicts of interest}

No potential conflict of interest relevant to this article was reported.

\section{References}

1. Wood LE, Tulloh RM. Kawasaki disease in children. Heart 2009;95: 787-92.

2. McCrindle BW, Rowley AH, Newburger JW, Burns JC, Bolger AF, Gewitz M, et al. Diagnosis, treatment, and long-term management of kawasaki disease: a scientific statement for health professionals from the American Heart Association. Circulation 2017;135:e927-99.

3. Newburger JW, Takahashi M, Burns JC. Kawasaki disease. J Am Coll Cardiol 2016;67:1738-49.

4. Singh S, Vignesh P, Burgner D. The epidemiology of Kawasaki disease: a global update. Arch Dis Child 2015;100:1084-8.

5. Daniels LB, Tjajadi MS, Walford HH, Jimenez-Fernandez S, Trofimenko V, Fick DB Jr, et al. Prevalence of Kawasaki disease in young adults with suspected myocardial ischemia. Circulation 2012;125: 2447-53.

6. Kawasaki T. [Acute febrile mucocutaneous syndrome with lymphoid involvement with specific desquamation of the fingers and toes in children]. Arerugi 1967;16:178-222.

7. Nakamura Y. Kawasaki disease: epidemiology and the lessons from it. 
Int J Rheum Dis 2018;21:16-9.

8. Kim GB, Park S, Eun LY, Han JW, Lee SY, Yoon KL, et al. Epidemiology and clinical features of Kawasaki disease in South Korea, 2012-2014. Pediatr Infect Dis J 2017;36:482-5.

9. Makino N, Nakamura Y, Yashiro M, Sano T, Ae R, Kosami K, et al. Epidemiological observations of Kawasaki disease in Japan, 20132014. Pediatr Int 2018;60:581-7.

10. Makino N, Nakamura Y, Yashiro M, Ae R, Tsuboi S, Aoyama Y, et al. Descriptive epidemiology of Kawasaki disease in Japan, 2011-2012: from the results of the 22nd nationwide survey. J Epidemiol 2015; 25:239-45.

11. Kim GB, Han JW, Park YW, Song MS, Hong YM, Cha SH, et al. Epidemiologic features of Kawasaki disease in South Korea: data from nationwide survey, 2009-2011. Pediatr Infect Dis J 2014;33:24-7.

12. Lin MT, Wu MH. The global epidemiology of Kawasaki disease: review and future perspectives. Glob Cardiol Sci Pract 2017;2017: e201720.

13. Ha S, Seo GH, Kim KY, Kim DS. Epidemiologic study on Kawasaki disease in Korea, 2007-2014: based on Health Insurance Review \&t Assessment Service Claims. J Korean Med Sci 2016;31:1445-9.

14. Huang WC, Huang LM, Chang IS, Chang LY, Chiang BL, Chen PJ, et al. Epidemiologic features of Kawasaki disease in Taiwan, 2003-2006. Pediatrics 2009;123:e401-5.

15. Lin MC, Lai MS, Jan SL, Fu YC. Epidemiologic features of Kawasaki disease in acute stages in Taiwan, 1997-2010: effect of different case definitions in claims data analysis. J Chin Med Assoc 2015;78:121-6.

16. Uehara R, Belay ED. Epidemiology of Kawasaki disease in Asia, Europe, and the United States. J Epidemiol 2012;22:79-85.

17. Chen JJ, Ma XJ, Liu F, Yan WL, Huang MR, Huang M, et al. Epidemiologic features of Kawasaki disease in Shanghai from 2008 through 2012. Pediatr Infect Dis J 2016;35:7-12.

18. Manlhiot C, O'Shea S, Bernknopf B, LaBelle M, Chahal N, Dillenburg RF, et al. Epidemiology of Kawasaki disease in Canada 2004 to 2014: comparison of Surveillance Using Administrative Data vs Periodic Medical Record Review. Can J Cardiol 2018;34:303-9.

19. Holman RC, Belay ED, Christensen KY, Folkema AM, Steiner CA, Schonberger LB. Hospitalizations for Kawasaki syndrome among children in the United States, 1997-2007. Pediatr Infect Dis J 2010;29: 483-8.

20. Mauro A, Fabi M, Da Frè M, Guastaroba P, Corinaldesi E, Calabri GB, et al. Kawasaki disease: an epidemiological study in central Italy. Pediatr Rheumatol Online J 2016;14:22.

21. Salo E, Griffiths EP, Farstad T, Schiller B, Nakamura Y, Yashiro M, et al. Incidence of Kawasaki disease in northern European countries. Pediatr Int 2012;54:770-2.

22. Sánchez-Manubens J, Antón J, Bou R, Iglesias E, Calzada-Hernandez J; Kawasaki Disease in Catalonia Working Group. Incidence, epidemiology and clinical features of Kawasaki disease in Catalonia, Spain. Clin Exp Rheumatol 2016;34(3 Suppl 97):S139-44.
23. García Rodríguez F, Flores Pineda ÁJ, Villarreal Treviño AV, Salinas Encinas DR, Lara Herrera PB, Maldonado Velázquez MDR, et al. Kawasaki disease at a pediatric hospital in Mexico. Bol Med Hosp Infant Mex 2016;73:166-73.

24. Hoyos-Bachiloglu R, García Á, Morales PS, Cerda J, Talesnik E, Borzutzky A. Geographic distribution of Kawasaki disease throughout Chile. Rev Chilena Infectol 2016;33:12-8.

25. Ulloa-Gutierrez R, Salgado AP, Tremoulet AH. Kawasaki disease in Latin American children: past, current, and future challenges. J Pediatric Infect Dis Soc 2014;3:280-1.

26. Kim GB, Park S, Kwon BS, Han JW, Park YW, Hong YM. Evaluation of the temporal association between Kawasaki disease and viral infections in South Korea. Korean Circ J 2014;44:250-4.

27. Nakamura Y, Yashiro M, Uehara R, Oki I, Watanabe M, Yanagawa H. Monthly observation of the number of patients with Kawasaki disease and its incidence rates in Japan: chronological and geographical observation from nationwide surveys. J Epidemiol 2008;18:273-9.

28. Son MBF, Newburger JW. Kawasaki disease. Pediatr Rev 2018;39:7890.

29. Zhang X, Liang Y, Feng W, Su X, Zhu H. Epidemiologic survey of Kawasaki disease in Inner Mongolia, China, between 2001 and 2013. Exp Ther Med 2016;12:1220-4.

30. Cimaz R, Fanti E, Mauro A, Voller F, Rusconi F. Epidemiology of Kawasaki disease in Italy: surveillance from national hospitalization records. Eur J Pediatr 2017;176:1061-5.

31. Saundankar J, Yim D, Itotoh B, Payne R, Maslin K, Jape G, et al. The epidemiology and clinical features of Kawasaki disease in Australia. Pediatrics 2014;133:e1009-14.

32. Tulloh RMR, Mayon-White R, Harnden A, Ramanan AV, Tizard EJ, Shingadia D, et al. Kawasaki disease: a prospective population survey in the UK and Ireland from 2013 to 2015. Arch Dis Child 2019;104: 640-6.

33. Jakob A, Whelan J, Kordecki M, Berner R, Stiller B, Arnold R, et al. Kawasaki disease in Germany: a prospective, population-based study adjusted for underreporting. Pediatr Infect Dis J 2016;35:129-34.

34. Shoham AB, Haklai Z, Dor M, Bar-Meir M. Rheumatic fever and Kawasaki disease among children in Israel. Harefuah 2014;153:70912 ,

35. Durongpisitkul K, Sangtawesin C, Khongphatthanayopthin A, Panamonta M, Sopontammarak S, Sittiwangkul R, et al. Epidemiologic study of Kawasaki disease and cases resistant to IVIG therapy in Thailand. Asian Pac J Allergy Immunol 2006;24:27-32.

36. Pinto FF, Laranjo S, Mota Carmo M, Brito MJ, Cruz Ferreira R. Twelve years of Kawasaki disease in Portugal: epidemiology in hospitalized children. Pediatr Infect Dis J 2017;36:364-8.

37. Tacke CE, Breunis WB, Pereira RR, Breur JM, Kuipers IM, Kuijpers TW. Five years of Kawasaki disease in the Netherlands: a national surveillance study. Pediatr Infect Dis J 2014;33:793-7. 